\title{
Level and trend of basic education of children in Bangladesh: 1993-1998
}

\author{
Samir R. Nath \\ Research Statistician \\ Research and Evaluation Division, BRAC \\ and \\ A. Mushtaque R. Chowdhury \\ Director Research, BRAC
}

November 1999

\section{BRAC}

Research and Evaluation Division

75 Mohakhali, Dhaka 1212, Bangladesh 


\begin{abstract}
Using data generated through two nationally representative sample surveys, this article explores the trends in the level of basic education of Bangladeshi children. The instrument used for the purpose was based on the Declaration of the World Conference on Education for All (WCEFA, Jomtien 1990). The findings reveal that the level of 'basic education' increased very slowly, 26.7 percent in 1993 to 29.6 percent in 1998, less than one percentage point per year. Statistically significant improvement was observed in 'life skills knowledge' and 'writing skills', but not in 'reading' or 'numeracy'. Girls progressed in 'reading', 'writing' and 'life skills' while the boys in 'writing' and 'life skills'. Over the period, the level improved for rural children but decreased for urban children. Bangladesh stands much behind to what was targeted at Jomtien Conference in 1990; it will have to wait until $2093 \mathrm{AD}$ to reach the WCEFA goal. The country has made good progress in increasing the access to primary education but a massive drive is necessary to improve the quality of education.
\end{abstract}

Keywords: Primary education; Jomtien Declaration; Quality of education; Trend; Bangladesh. 


\section{Introduction}

The World Conference on Education for All (WCEFA) held in Jomtien in 1990 had led to remarkable educational efforts world wide (King, 1993; Buchert, 1995; McIntosh, 1999). The Conference urged the participating nations to provide basic education to at least 80 percent of the children of primary school age group (WCEFA, 1990). It not only reiterated the educational needs of the people, but also for the first time, emphasised quality matters along with the expansion of education (Youngman, 1993; Bergman, 1996). The Conference Declaration defined basic education as education intended to meet basic learning needs, which in turn was defined as knowledge, skills, attitudes and values necessary for the people to survive, to improve the quality of their lives, and to continue learning (WCEFA, 1990).

As a signatory to the Jomtien Declaration, Bangladesh is committed to impart basic education to its children (Primary and Mass Education Division, 1995). After the conference, new attempts have been made to expand educational opportunities among children including disadvantaged groups, and to improve the quality of education through improved curricula and innovative projects. Readers are referred to a companion article in this issue for more information in this regard.

At present there are many types of institutions that provide primary level education in Bangladesh. The State owned schools, however, are dominant with over two-thirds of the total enrolments (Chowdhury et al, 1999). Fifteen percent of the students enrol in non-government primary schools (registered and un-registered), 8.5 percent in NGO (non- governmental organisation) operated non-formal schools, 5.9 percent in madrassas ${ }^{l}$ and 2.9 percent in others types. The net enrolment rate at primary stage is 77 percent and the attendance rate is 62 percent. Nearly 73 percent of the enrolled children complete the five year cycle of primary education, of which 38 percent are repeaters. Gender parity in terms of enrolment, attendance and completion has been achieved recently. The adult

\footnotetext{
'These schools provide education with special emphasis on Islamic principle. Curricula of these schools are developed by an independent Board. These schools may be State owned or privately managed.
} 
literacy rate, according to government statistics, has increased from 34.6 percent in 1990 to 51.2 percent in 1998 (Bangladesh Bureau of Education Information and Statistics, 1992; UNICEF, 1998). Regional variations persist in different internal efficiency indicators of education (Chowdhury et al, 1999).

Attempts were made, mostly at non-governmental levels, to monitor the progress in the primary education situation. Borrowing the concept of basic education from the Jomtien Declaration, a practical methodology and measuring instrument were developed in the early 1990's (Chowdhury et al, 1992; Chowdhury et al, 1994) and two national surveys were conducted in 1993 and 1998 for measuring the quality of basic education. Using the data generated through these surveys, this article explores the changes and dimensions in the level of basic education of children in Bangladesh.

\section{Methodology}

The methodology and the assessment instrument, used for this study, were developed in Bangladesh in 1992 (Chowdhury et al, 1992; Chowdhury et al, 1994). In doing so, the definitions of 'basic education' and 'basic learning needs' as recommended by the WCEFA were adopted, and the following definition of 'basic education' was set for Bangladesh:

Basic education will refer to education intended to develop basic learning skills (i.e., the $3 R$ 's) as well as some basic life skills necessary for the children to survive, to improve the quality of their lives and to continue learning.

The instrument used for the study was curriculum independent, but the competencies measured through this instrument were very basic among those terminal competencies expected to be achieved through primary schooling in Bangladesh (National Curriculum and Textbook Board, 1988). It addressed four competencies: reading, writing, numeracy and life skills/knowledge. The items/questions chosen were based upon the goals of the

$$
276
$$


Education for All (EFA) and country's official definition of literacy. The following describes the items/questions under different competencies.

Life skills: There were ten questions which tested child's knowledge of issues relevant to development. These include knowledge on health and hygiene, poultry and livestock, population, basic attitude towards gender equity, and the outside world. Children answering 'correctly' at least seven of the ten questions were considered to have 'life skills/knowledge'.

Reading: The children were given a short passage of seven sentences to read loudly or to him/herself, and afterwards were asked four questions. The passage was simple, described traditional Bangladeshi life and conveyed important development message related to savings, small family and schooling. The questions were both direct and indirect. Children answering 'correctly' at least three of the four questions from the 'reading comprehension passage' were considered to have 'reading skills'.

Writing: The child was asked to write a letter to his/her father or other relative to communicate a given message. It should be mentioned that a person's capacity in communicating through letters is an important element of the definition of literacy used in the national censuses in Bangladesh. Children 'correctly' communicating the given message through letter were considered to have 'writing skills'.

Numeracy: The children were asked to solve four mental arithmetic problems needing skills in addition, subtraction, multiplication and division. These problems were related to situations that occur in day-to-day life of the children. Children answering 'correctly' at least three questions were considered to have 'numeracy skills'.

Children satisfying all the four criteria of reading, writing, numeracy and life skills/knowledge were considered to have 'basic education'. 
A group of experts worked in the development of the instrument confirming its content validity (Chowdhury et al, 1992; Chowdhury et al, 1994). A linear positive relationship between the performance in each of the items and the years of schooling of the children, and statistically significant positive relationship between parental education and children's level of basic education confirmed its internal validity (Nath et al, 1993; Chowdhury et al, 1999). A wide variation in achievement was observed between the children of 'poor' and 'good' schools, and between the 'poor' and the 'good' students in a class (Chowdhury et al, 1994). All these evidences indicate the validity of the test instrument used in the study.

\section{Study population}

The official primary schooling age in Bangladesh is 6-10 years (Government of Bangladesh, 1990). We assessed the level of basic education of the children just above this age range, viz., 11-12 years, irrespective of schooling. Thus, the population of this study included all children of Bangladesh aged 11-12 years in 1993 and 1998.

\section{Sampling strategy}

The basic educational achievement of the children was assessed dichotomously, i.e., each child either had or had not attained it. For a precision level of $7 \%$ with $95 \%$ confidence limit, it was estimated that a sample of 196 is necessary to have a single estimate (Cochran, 1977; Kalton, 1983). As cluster-sampling approach was followed in the surveys, the sample size was doubled to reduce cluster effect on the estimate. The required sample size for an estimate thus stood at 392 .

The 1993 national survey on basic education contained six sub-national surveys, of which five were in the then five rural administrative divisions and one in urban Bangladesh. On the other hand, in 1998, eight sub-national surveys were carried out. Of these, six were in six rural administrative divisions, one in the metropolitan cities and the rest one in the non-metropolitan urban areas. A three stage sampling strategy was followed in both the 
surveys. At the first stage, 30 thanas $^{2}$ (pourasava for urban areas) were selected through systematic random sampling technique with probability proportional to size (PPS). At the second stage, one union ${ }^{3}$ (ward for urban strata) for each selected thana/pourasava was selected randomly. At the third stage, one village ${ }^{4}$ (mahallah for urban strata) was randomly selected from each selected union/ward. This means that 30 villages/mahallahs (here called cluster) were selected for each stratum, totalling 180 for the 1993 survey and 240 for the 1998 survey. From each cluster 14 children aged 11-12 years, irrespective of schooling, were selected following a systematic random sampling procedure. Thus, each cluster contained 420 children. Table 1 shows more details of the sample.

\section{Table 1 is about here}

The data collection for the first survey was done in February 1993 and the second survey in October-November 1998; about 5.5 years between the two surveys. Details about the fieldwork procedure of the surveys are available in Nath et al (1993) and Chowdhury et al (1999).

\section{Reliability of data}

The reliability of the data was assessed in two ways. Firstly, re-interviews of some selected items of sub samples were done within one week of the main interview. The matching operation between the data of the main interview and the re-interview in both surveys showed perfect match over in 90 percent of the cases. Using 'Test-retest method' (Gupta and Kapoor, 1994) the reliability coefficient was found to be 0.96 and 0.93 respectively for 1993 and 1998 data. Secondly, Kudar-Richardson formula number 20 (KR 20) was used to find the reliability coefficient (Kudar and Richardson, 1937; Carmines and Zeller, 1979). The coefficient was found to be 0.88 for 1993 and 0.96 for 1998. All these coefficients are much higher than the satisfactory level of 0.80 (Carmines et al, 1979).

\footnotetext{
2 Thana: A government administrative unit with an average population of 260,000.

${ }^{3}$ Union/ward: A local government unit with an average population of 22,000 .

4 Village/Mahalla: The smallest component of the local government unit, with an average household of 250 and population of 1,250 .
} 


\section{Data analysis technique}

To find the level of attainment of the interviewed children bi-variate analysis was done for 'basic education' and its different components. In each case, data were arranged by survey year, sex and area of residence (rural/urban). Appropriate statistical test (chi squire) was performed to identify the significance of the variations among the estimates. As strata population varied substantially appropriate weights were used to calculate the aggregate estimates.

\section{Results}

\section{Trends in the level of basic education}

Using the working definition of basic education as mentioned earlier, 26.7 percent of the surveyed children satisfied all four criteria of basic education in 1993 which rose to 29.6 percent after five-and-a-half years in $1998(\mathrm{p}<0.05)$ (Table 2). While the level of basic education of the rural children increased from 23.4 percent in 1993 to 26.5 percent in 1998 ( $\mathrm{p}<0.05)$, it decreased in urban areas, from 55.7 percent in 1993 to 48.4 percent in 1998 ( $p<0.05$ ). Although the boys did better than the girls in both the surveys, the gender gap became statistically significant in $1998(\mathrm{p}<0.05)$. This happened because the urban girls performed significantly worse than boys in 1998. No gender variation was observed among the rural children in any of the surveys. In both the surveys urban children showed significantly better performance than their rural counterparts $(p<0.001)$; similar results were found when the data were arranged for girls and boys separately.

\section{Table 2 is about here}

Children were considered to have 'partial basic education' if they satisfied between one and three criteria of 'basic education'. As the level of 'basic education' increased between 1993 and 1998 the levels of 'partial basic education' and 'no basic education' decreased. In 1993, 59 percent of the children had 'partial basic education' and 14.3 percent had 'no basic education'. In 1998, the level of 'partial' and 'no' basic education reduced to 57.6 percent and 12.8 percent respectively. Gender wise arrangement of the 
data shows that proportion of girls attaining 'no basic education' reduced from 19.4 percent in 1993 to 16.4 percent in 1998 . However, it remained same for the boys in both the years.

Table 3 presents the trends in the levels of the four competencies between the two surveys. In both the surveys, the performance in 'life skills knowledge' was poor, but it was very good in 'numeracy'. A moderate performance was observed in 'reading' and 'writing'. In 'life skills/knowledge' the level, however, significantly increased from 35.6 percent in 1993 to 43.3 percent in 1998 ( $p<0.001)$. The increase was seen more among the children of rural areas than the urban areas. Increased performance was also observed separately for both boys and girls $(\mathrm{p}<0.001)$.

Table 3 is about here

There was no significant improvement in the level of 'reading skills' of the children over the period of five and a half years. On average, a half of the interviewed children satisfied the criteria for reading skills in both the surveys. The performance of the rural children did not change much between the surveys, but it significantly decreased for the urban children $(\mathrm{p}<0.01)$. Although boys had achieved better than girls in 'reading skills' in 1993 ( $\mathrm{p}<0.001)$, the gap disappeared by 1998 .

In 'writing skills', the performance of the children increased significantly from 44.1 percent in 1993 to 51.4 percent in $1998(\mathrm{p}<0.001)$. The increase was seen more in rural areas than in the urban areas. Overall, the increase was observed equally in girls and boys. Although boys performed better than the girls in $1993(p<0.001)$, no gender variation was found in 'writing skills' in 1998.

In terms of 'numeracy skills', no aggregate change was observed over the period. The performance, however, significantly deteriorated for urban children $(\mathrm{p}<0.01)$. Boys who showed better performance in 1993 continued to do so in 1998, even when the data were arranged for urban and rural children separately. 
In sum, the urban children did significantly better than the rural children in all the assessment areas in both the surveys $(p<0.001)$. Over the period, the rural children showed improvement in 'life skills' and 'writing' while the urban children deteriorated in 'reading' and 'numeracy'. Gender wise, girls showed improvements in three areas: 'life skills', 'reading' and 'writing' while the boys in two: 'life skills' and writing'.

\section{Trends in literacy level}

'Literacy' includes all the criteria of 'basic education' minus 'life skills/knowledge'. In other words, it is nothing but the $3 \mathrm{R}$ 's. We have analysed the data with this criterion as well. This was done because some may argue that although it is important to achieve basic life skills/knowledge for a child, it is not equally emphasised in all types of primary education provisions in Bangladesh. Thus, for comparison among different types of schools 'literacy' is suitability preferred.

\section{Table 4 is about here}

Similar to 'basic education', the 'literacy' level increased between 1993 and 1998, from 39.6 percent to 42.5 percent $(p<0.05$ ) (Table 4 ). Area wise arrangement of the data shows that the 'literacy' level increased for rural children $(p<0.05)$, but decreased for urban children $(p<0.01)$. The gender difference in literacy in favour of boys was found in both the surveys, but the gap narrowed over the period. It is interesting to observe that while the rural girls have overcome the gender gap over the period, the urban girls could not do so. Similar to 'basic education', rural children were lagging behind their urban counterparts in 'litcracy' level in both the surveys ( $p<0.001)$.

\section{Schooling and achievement}

To understand the relationship between the level of 'basic education' and 'literacy' with schooling, the level of performance was analysed by number of years of schooling completed by the children (Tables 5 and 6). It was observed that both 'basic education' and 'literacy' significantly increased with years of schooling $(\mathrm{p}<0.001)$. Similar results 
were found when data were analysed separately for rural and urban children. However, if we look at the difference in the achievement levels between urban and rural children against each of the completed year, it is found that rural children showed poorer performance at each grade of learning, and that the rural children lagged behind urban children by at least one year. This is true for both 1993 and 1998. However, at each stage of learning the level of achievement increased over time. It is clear from the findings of the Tables 5 and 6 that it was not possible for the children of Bangladesh to achieve the WCEFA goal for 'basic education' through five-year cycle of primary education, even not with an additional year of secondary schooling. However, among the children of six or more years of schooling, over 80 percent had satisfied 'literacy' criteria. The quality of primary education has possibly improved over the period. For children completing five years of schooling, the level of 'basic education' increased from $\mathbf{4 2 . 2}$ percent in 1993 to 56.9 percent in 1998 (Table 5), and the 'literacy' level increased from 64.9 percent to 73.9 percent respectively (Table 6). These increases are statistically significant.

Tables $5 \& 6$ are about here

The students of different types of schools did not achieve equally. The children of State owned formal schools performed poorly, and the children of non-formal schools performed significantly better than those of other types of schools.

\section{Years needed to achieve WCEFA goal}

According to the Declaration of the Jomtien Conference the participating nations are committed to impart basic education to at least 80 percent of the school aged children. Assuming that the level tested through the $A B C$ represented the basic minimum for 'basic education', an attempt was made to measure how far behind the Bangladeshi children aged 11-12 years from this goal. Table 7 shows that Bangladeshi children aged 11-12 years would need a staggering 95 years more to reach the goal, similar for both boys and girls. Even the children who completed the five year cycle of primary education were also behind the WCEFA goal. As the rate of increase observed between 
1993 and 1998, it will take eight years more to achieve WCEFA goal, separately five years for boys and 14 years for girls. The above analysis indicate that Bangladeshi children aged 11-12 years would not meet the WCEFA goal of 'basic education' until $2093 \mathrm{AD}$, and it would need to wait until $2006 \mathrm{AD}$ to achieve the same by the children completing five year cycle of primary education. If the analysis is done without considering the 'life skills/knowledge' the nation would need 71 years to provide 'literacy' to 80 percent of its children and only four years among those completing the primary cycle.

\section{Table 7 is about here}

\section{Discussion and conclusion}

This paper examined the progress made in the level of basic education for the children in Bangladesh between 1993 and 1998. Data generated through two nationally representative sample surveys conducted during those two periods were used for the purpose. A same instrument was used in the surveys which was developed on the basis of ideas and concepts expounded in the Declaration of the World Conference on Education for All (WCEFA), 1990. Following the Conference many steps were taken by the government and the non-government agencies in Bangladesh to increase the access in education and to improve the quality of education at primary level. According to the National Plan of Action on education, the government of Bangladesh is committed to the goals of the Jomtien Conference (Primary and Mass Education Division, 1995). It may be mentioned that the WCEFA Declaration called upon the participating nations to impart basic education to 80 percent of its school aged children by 2000 AD (WCEFA, 1990).

According to the findings presented in this paper the level of 'basic education' of children aged 11-12 years significantly increased between 1993 and 1998 from a low baseline of 26.7 percent. However, the rate of increase has been too slow, only 0.53 percentage point a year, which indicates that Bangladesh is progressing very slowly in ensuring basic education for its children. Although there was little gender variation in the achievement level five-and-a-half years ago, disparity against girls has become a reality by 1998 , 
which was mostly confined among urban children. There is also an overall decrease in the basic educational achievement in urban areas between the two periods. There has been an enormous increase in the urban population of the country in recent years, but concomitant increase in the services have not taken place leading to a deterioration of the urban situation.

Skill wise analysis of the data showed that children continued to do very well in 'numeracy' but worst in 'life skills'. Although, the performance in life skills knowledge significantly increased over the period, nearly 60 percent of the children could not attain the minimum level in this area. The reason behind this poor performance might be attributed to the insignificant attention given to this issue. Although the Jomtien Conference strongly advocated for life skills knowledge along with the $3 \mathrm{R}$ 's, no special effort was given in this area by the mainstream schools in Bangladesh. However, the non-government organisations emphasised the issue in their non-formal education system. Good performance of children from the non-formal education programmes in basic life skills is supported by many studies conducted in recent years (Nath and Chowdhury, 1996; Nath, 1997; Nath et al, 1998, Nath et al, 1999).

The performance of the children was also not satisfactory in reading and writing; slightly over a half of the children satisfied the minimum levels in these two assessment areas. Although the girls were less competent than the boys in reading and writing in 1993, interestingly the gender gap disappeared in these areas when examined in 1998. Reduction of gender gap with the increase of level in writing skills was a good indication of progress. Schools in Bangladesh need to give greater emphasis on reading, writing and life skills. Although the children showed very good performance in numeracy, gender disparity against girls was observed in both the surveys. Other studies in Bangladesh also indicated such difference between boys and girls (Nath et al, 1997; Nath, 1998). Good performance in numeracy is understandable since the items taken for the assessment are very simple and cover situations that occur in everyday life. Gender disparity in numeracy should be handled seriously. Data analysis by years of schooling showed that 
the girls were lagging behind the boys in numeracy at each grade of learning. The gender difference occurred even in children who never been to school (Nath et al, 1997). No attempt has been made in Bangladesh towards equity in mathematics and science. Many developed countries removed the disparity at primary stage, Bangladesh may take lessons from them. Statistically significant improvement in the level of basic education of rural children is noteworthy, but their performance level was very poorly compared to their urban counterparts. It was clearly observed that rural children were lagging at least one year behind their urban counterparts. About 80 percent of the Bangladeshi children live in rural areas, and overall national progress depends largely on the development of these children. The WCEFA Declaration, however, emphasised on equity, Bangladesh is yet to achieve it in the areas of basic learning attainments.

The study observed that Bangladesh is far behind of what is expected by the WCEFA Declaration. The country will have to wait until $2093 \mathrm{AD}$ to achieve the basic educational goal for 2000, meaning that Bangladesh is still 94 years behind the desired time. To understand the standard of our primary education let us take a look at those children who completed the five year cycle of primary education. The WCEFA goal was not attained even among them. However, the level of progression was faster among this group compared to what happened in all children. The rate of increase was higher among boys than girls. This means that the goal can probably be reached earlier if the present enrolment and completion rates are increased rapidly. At present, 77 percent of the primary schooling age children are in schools, and the five year cycle completion rate is 73 percent, of which only 48 percent complete it in due time (Chowdhury et al., 1999). This means that 32 percent $(.77 \times .73 \times .57)$ of the school going children receive some meaningful education, and only 21 percent $(.77 \times .48 \times .57)$ of the same get it in due course. Greancy et al (1998) also raised questions about the quality of primary and secondary schooling in Bangladesh.

Now the question is what Bangladesh can do in providing basic education to all children at their right ages. The data used in this study and other studies indicated that children of 
Bangladesh do not enrol in school at their right ages (i.e., at age six as mentioned in the Compulsory Primary Education Act 1990). Thus, only a few children receive full course of primary education at the age determined by the government. Steps should be taken to enrol all children in school at age six. This statement may contradict with the policy of the non-formal education programmes, because, the debate between formal and nonformal education is not just a curriculum problem but of age too. Non-formal programmes generally consider the children who missed the opportunity to be educated at their right ages. It is obvious that this opportunity should be continued until the country reaches the goal of EFA. On the other hand, nearly $90 \%$ of the currently enrolled children are covered by the formal systems and parents/guardians of the $37 \%$ of the non-enrolled children (aged 6-10 years) think that these kids are 'too young to go to school' (Chowdhury et al., 1999). Thus, attempts may be taken at parents/guardians level to improve the situation. In Bangladesh, the formal school students are to sit in exams at the end of each grade. If the students fail to secure minimum marks (33\% separately in each subject area) they are not promoted to the next grade. These students repeat for more years in the same grade and delays completion. To reduce such repetition grade wise required level of lessons should be ensured to the students. The teachers and the local education administration need to be active in this regard. The wide gap that exists between current level of basic education and the goal, Bangladesh needs to revise the goal according to its capacity. Again, if the country has to wait so long to achieve such a minimum level of basic education it will fall far behind other developing countries, and would fail to meet the challenges of the new millennium. The only way to meet the challenge is to give a highest effort in ensuring quality education for all its children. The Compulsory Primary Education Act concentrated only on the enrolment of children; it says nothing about the quality of education (Government of Bangladesh, 1990). The Act has rightly emphasised enrolment but it also needs to emphasise quality; an amendment is thus imperative. Criteria for minimum standard of quality education may be set in the Act and responsibility may be given to the compulsory primary education committees (both local and national levels) to ensure the minimum standard. A monitoring system 
may be adopted and results of this exercise may be made public at local and national levels.

The data also suggest that the performance of the students of government primary schools was poorer than the students of other types. Given that such schools enrol over two thirds of the students at primary level (Chowdhury et al, 1999), more input is thus required on the State run primary schools to have maximum impact. The government often claims that education is given priority in budgetary allocation, however, this allocation is much less than what is expected. Only 2.3 percent of the gross national product (GNP) is spent on education (Haq and Haq, 1998). Moreover, much of this is spent to meet teacher salary and other administrative matters leaving very little for academic development (Ahmed et al, 1993; Chowdhury et al, 1999). Increased allocation as well as redistribution of education budget should be seriously considered for the sake of quality basic education.

\section{Acknowledgements}

The first survey was financed by UNICEF and the second survey was funded by NOVIB of Holland, Sida, UNESCO and BRAC. The Research and Evaluation Division of BRAC shouldered the implementation of the surveys and the Campaign for Popular Education (CAMPE) provided secretariat during second survey. The authors are grateful to above organisations for their help. The individuals who served in the Advisory Board and the Working Committee also deserve acknowledgements. Thanks to the field investigators, the children interviewed and the referees reviewed the earlier version of the paper. 


\section{References}

Ahmed, M., Chabbott, C., Joshi, A., Pande, R., Prather, C. J., 1993. Primary education for all: Learning from $B R A C$ experience, $A$ case study. Advancing Basic Education and Literacy (ABEL), New York.

Bangladesh Bureau of Education Information and Statistics, 1992. Bangladesh Education Statistics 1991. Bangladesh Bureau of Education Information and Statistics, Dhaka.

Bergmann, H., 1996. Quality of education and the demand for education - evidence from developing countries. International Review of Education, 42, 581-604.

Buchert, L., 1995. The concept of education for all: What has happened after Jomtien? International Review of Education, 41, 537-549.

Carmines, E. G., Zeller, R. A., 1979. Reliability and validity assessment. Sage University Paper series on Quantitative Applications in the Social Sciences, 07-017. Sage, Newbury Park, CA.

Chowdhury, A. M. R., Choudhury, R. K., Nath S. R. (Eds.), 1999. Hope not complacency-state of primary education in Bangladesh 1999. Campaign for Popular Education and University Press Limited, Dhaka.

Chowdhury, A. M. R., Ziegahn, L., Haque, N., Shrestha, G. L., Ahmed, Z., 1994. Assessing basic competencies: A practical methodology. International Review of Education, 40, 437-454.

Chowdhury, A. M. R., Mohsin, M., Nath, S. R., 1992. Assessment of basic education of the children in Bangladesh. BRAC, Dhaka.

Cochran, W. G., 1977. Sampling techniques. John Wiley \& Sons, Singapore.

Government of Bangladesh, 1990. Primary Education (Compulsory) Act 1990. Bangladesh Gazette, Vol. 5, Additional issue, February 1990. Government of Bangladesh, Dhaka (in Bangla).

Greancy, V., Khandker, S. R. Alam, M., 1998. Bangladesh: assessing basic learning skills. University Press Limited, Dhaka.

Gupta, S. C., Kapoor, V. K., 1994. Fundamentals of applied statistics. Sultan Chand \& Son, New Delhi.

Haq, M., Haq K., 1998. Human development in South Asia. The University Press Limited, Dhaka. 
Kalton, G., 1983. Introduction to survey sampling. Sage University Paper series on Quantitative Applications in the Social Sciences, 07-035. Sage, Newbury Park, CA.

King, K., 1993. Education for all: National and international implications. Compare, 23, 5-8.

Kuder, G. F., Richardson M. W., 1937. The theory of the estimation of test reliability. Psychometrika, 2, 151-160.

McIntosh, C., 1999. Editorial Introduction. International Review of Education, 45, 1-3.

Nath, S. R., 1997. The impact of BRAC's education programme on raising basic education levels for the children of rural Bangladesh [dissertation]. University of Oxford, Oxford.

Nath, S. R., 1998. Gender difference in mathematics achievement among the graduates of BRAC schools. BRAC, Dhaka.

Nath, S. R., Chowdhury, A. M. R., 1996. Basic competencies of the graduates of BRAC schools of 1995. BRAC, Dhaka.

Nath, S. R., Imam, S. R., Chowdhury, A. M. R., 1998. Levels of basic competencies of the BRAC school graduates of 1995 and 1997. BRAC, Dhaka.

Nath S. R., Mohsin, M., Chowdhury A. M. R., 1997. Gender difference in the arithmetical knowledge of children in Bangladesh. Research in Education, 58, 35-45.

Nath, S. R., Mohsin, M., Chowdhury, A. M. R., 1993. Assessment of basic competencies of the children in Bangladesh 1993. BRAC, Dhaka.

Nath, S. R., Sylva, K., Grimes, J., 1999. Raising basic education levels in rural Bangladesh: the impact of a non-formal education programme. International Review of Education, 45, 5-26.

National Curriculum and Textbook Board, 1988. Sarboganin prathomik shiksar pathabhumite shikshskram parimargon o nabayan karyakram: aabashakeea shiksankram. National Curriculum and Textbook Board, Dhaka (in Bangla).

Primary and Mass Education Division, 1995. Education for all: national plan of action. Primary and Mass Education Division, Government of the Peoples' Republic of Bangladesh, Dhaka.

UNICEF, 1998. Progotir Pathey- achieving the goals for children in Bangladesh. UNICEF, Dhaka. 
World Conference on Education for All (WCEFA), 1992. Education for all: An expanded vision. UNESCO, Paris.

World Conference on Education for All (WCEFA), 1990. World declaration on education for all and framework for action to meet basic learning needs. The InterAgency Commission for the World Conference on Education for All, New York.

Youngman, F., 1993. Basic education in Botswana: A review of the national conference on education for all, Gaborone, June 1991. Compare, 23, 15-24. 
Table 1: Study sample at a glance

\begin{tabular}{lllllllll}
\hline $\begin{array}{l}\text { Survey } \\
\text { year }\end{array}$ & $\begin{array}{l}\text { No. of } \\
\text { districts }\end{array}$ & $\begin{array}{l}\text { No. of } \\
\text { strata }\end{array}$ & Boys & Girls & & Boys & Girls & Total \\
\hline 1993 & $62^{*}$ & 6 & 1,044 & 1,056 & 201 & 219 & 2,520 \\
1998 & 64 & 8 & 1,261 & 1,259 & & 419 & 421 & 3,360
\end{tabular}

* Two districts were not included in the sampling frame due to political unrest in the areas

Table 2: Percentage of children satisfying basic education criteria by area of residence, sex of children and year

\begin{tabular}{|c|c|c|c|c|c|c|c|c|c|}
\hline \multirow{2}{*}{ Year } & \multicolumn{3}{|c|}{ Rural } & \multicolumn{3}{|c|}{ Urban } & \multicolumn{3}{|c|}{ All } \\
\hline & Boys & Girls & Both & Boys & Girls & Both & Boys & Girls & Both \\
\hline 1993 & 24.5 & 21.7 & 23.4 & 58.7 & 53.0 & 55.7 & 28.4 & 25.0 & 26.7 \\
\hline 1998 & 27.8 & 25.2 & 26.5 & 52.7 & 44.2 & $48.4^{*}$ & 31.3 & 27.9 & $29.6^{*}$ \\
\hline Remarks & $n s$ & $n s$ & $p<.05$ & $n s$ & $p<.05$ & $p<.05$ & $n s$ & $n s$ & $p<.01$ \\
\hline
\end{tabular}

Notes: Differences between rural and urban areas are statistically significant $(\mathrm{p}<0.001)$ in all six cases;

${ }^{*} \mathrm{p}<.05 ; \quad \mathrm{ns}=$ Not significant at $\mathrm{p}=.05$ 
Table 3: Percentage of children satisfying different components of basic education by area of residence, sex of children and year

\begin{tabular}{|c|c|c|c|c|c|c|c|c|c|}
\hline \multirow{2}{*}{ Year } & \multicolumn{3}{|c|}{ Rural } & \multicolumn{3}{|c|}{ Urban } & \multicolumn{3}{|c|}{ All } \\
\hline & Boys & Girls & Both & Boys & Girls & Both & Boys & Girls & Both \\
\hline \multicolumn{10}{|c|}{ Life skills/knowledge } \\
\hline 1993 & 32.5 & 31.4 & 32.4 & 63.7 & 63.9 & 63.8 & 36.2 & 34.8 & 35.6 \\
\hline 1998 & 41.3 & 38.2 & 39.6 & 66.8 & 64.1 & 65.4 & 45.0 & 41.9 & 43.3 \\
\hline Remarks & $p<.001$ & $p<.01$ & $p<.001$ & $n s$ & $n s$ & $n s$ & $p<.001$ & $p<.001$ & $p<.001$ \\
\hline
\end{tabular}

\section{Reading skills}

$\begin{array}{llllllllll}1993 & 52.9 & 46.3 & 50.2 \ddagger & 80.6 & 74.0 & 77.1 & 56.5 & 49.2 & 52.9 \ddagger \\ 1998 & 51.8 & 51.3 & 51.6 & 73.3 & 62.2 & 70.2 & 54.9 & 52.9 & 54.2 \\ \text { Remarks } & n s & p<.05 & n s & p<.05 & n s & p<.01 & n s & p<.05 & n s\end{array}$

Writing skills

$\begin{array}{llllllllll}1993 & 43.8 & 37.4 & 41.2 \ddagger & 75.6 & 64.4 & 69.8^{*} & 47.8 & 40.3 & 44.1 \ddagger \\ 1998 & 49.1 & 48.6 & 48.9 & 68.5 & 64.0 & 66.6 & 51.9 & 50.9 & 51.4 \\ \text { Remarks } & p<.05 & p<.001 & p<.001 & n s & n s & n s & p<.05 & p<.001 & p<.001\end{array}$

\section{Numeracy skills}

$\begin{array}{llllllllll}1993 & 86.2 & 74.7 & 81.4 \ddagger & 96.5 & 88.1 & 92.1 \ddagger & 88.7 & 76.1 & 82.4 \ddagger \\ 1998 & 88.3 & 77.3 & 82.8 \ddagger & 93.8 & 80.1 & 86.9 \ddagger & 89.1 & 77.7 & 83.4 \ddagger \\ \text { Remarks } & n s & n s & n s & n s & p<.01 & p<.01 & n s & n s & n s\end{array}$

Notes: Differences between rural and urban areas are statistically significant $(\mathrm{p}<0.001)$ in all 24 cases;

$* \mathrm{p}<.05 ; \quad \ddagger \mathrm{p}<.001 ; \quad \mathrm{ns}=$ Not significant at $\mathrm{p}=.05$ 
Table 4: Percentage of children satisfying literacy criteria (the $3 \mathrm{R}$ 's) by area of residence, sex of children and year

\begin{tabular}{|c|c|c|c|c|c|c|c|c|c|}
\hline \multirow{2}{*}{ Year } & \multicolumn{3}{|c|}{ Rural } & \multicolumn{3}{|c|}{ Urban } & \multicolumn{3}{|c|}{ All } \\
\hline & Boys & Girls & Both & Boys & Girls & Both & Boys & Girls & Both \\
\hline 1993 & 39.4 & 32.9 & $36.6 \pm$ & 72.6 & 60.7 & $66.4 \dagger$ & 43.4 & 35.7 & $39.6 \ddagger$ \\
\hline 1998 & 41.1 & 38.5 & 39.8 & 62.7 & 54.0 & $58.3 \dagger$ & 44.2 & 40.8 & $42.5^{*}$ \\
\hline Remarks & ns & $p<.01$ & $p<.05$ & $p<.05$ & ns & $p<.01$ & ns & $\mathrm{p}<.01$ & $\mathrm{p}<.05$ \\
\hline
\end{tabular}

Notes: Differences between rural and urban areas are statistically significant $(\mathrm{p}<0.001)$ in all six cases;

${ }^{*} \mathrm{p}<.05 ; \quad \quad \mathrm{p}<.01 ; \quad \ddagger \mathrm{p}<.001 ; \quad \mathrm{ns}=$ Not significant at $\mathrm{p}=.05$

Table 5: Percentage of children satisfying basic education criteria by years of schooling completed, area of residence and year

\begin{tabular}{lccccccc}
\hline \multirow{2}{*}{$\begin{array}{l}\text { Years of } \\
\text { schooling }\end{array}$} & \multicolumn{3}{c}{1993} & & \multicolumn{3}{c}{1998} \\
\cline { 3 - 4 } & Rural & Urban & All & & Rural & Urban & All \\
\hline One & 4.1 & 0.0 & 3.8 & & 7.7 & 6.8 & 7.6 \\
Two & 1.9 & 15.0 & 2.6 & & 15.5 & 21.3 & 16.2 \\
Three & 13.8 & 33.3 & 15.2 & & 18.7 & 37.5 & 20.8 \\
Four & 28.8 & 43.5 & 30.0 & & 37.7 & 52.5 & 39.9 \\
Five & 38.5 & 66.3 & 41.7 & & 53.2 & 73.5 & 56.9 \\
Six + & 58.2 & 85.6 & 64.1 & & 63.0 & 91.6 & 70.8 \\
Remarks & $p<.001$ & $p<.001$ & $p<.001$ & & $p<.001$ & $p<.001$ & $p<.001$ \\
& & & & & & & \\
\hline
\end{tabular}

Note: Children without schooling could not satisfy the criteria of basic education 
Table 6: Percentage of children satisfying literacy (the $3 \mathrm{R}$ 's) criteria by years of schooling completed, area of residence and year

\begin{tabular}{lccccccc}
\hline \multirow{2}{*}{$\begin{array}{l}\text { Years of } \\
\text { schooling }\end{array}$} & \multicolumn{3}{c}{1993} & & \multicolumn{3}{c}{1998} \\
\cline { 2 - 4 } & Rural & Urban & All & & Rural & Urban & All \\
\hline One & 5.6 & 5.0 & 5.6 & 11.4 & 6.8 & 10.8 \\
Two & 7.9 & 20.0 & 8.5 & 22.1 & 31.9 & 23.3 \\
Three & 28.6 & 41.7 & 29.5 & 38.0 & 51.6 & 39.5 \\
Four & 47.3 & 66.1 & 48.8 & & 57.8 & 68.8 & 59.5 \\
Five & 62.5 & 83.1 & 64.9 & & 71.4 & 85.3 & 73.9 \\
Six + & 78.4 & 93.1 & 81.6 & & 82.6 & 95.8 & 86.2 \\
Remarks & $p<.001$ & $p<.001$ & $p<.001$ & & $p<.001$ & $p<.001$ & $p<.001$ \\
& & & & & & & \\
\hline
\end{tabular}

Note: Children without schooling could not satisfy the criteria of 'literacy'

Table 7: Projected year at which Bangladesh can meet the WCEFA goal of basic education, for all children and children completing five years of schooling

\begin{tabular}{|c|c|c|c|c|c|c|}
\hline & \multicolumn{3}{|c|}{ All children } & \multicolumn{3}{|c|}{ Children completing grade $\mathrm{V}$} \\
\hline & Boys & Girls & Both & Boys & Girls & Both \\
\hline Level at $1993(\%)$ & 28.4 & 25.0 & 26.7 & 41.2 & 42.3 & 41.7 \\
\hline Level at $1998(\%)$ & 31.3 & 27.9 & 29.6 & 61.9 & 52.9 & 56.9 \\
\hline Total increase (\%) & 2.9 & 2.9 & 2.9 & 20.7 & 10.6 & 15.2 \\
\hline Increase per year (\%) & 0.53 & 0.53 & 0.53 & 3.8 & 1.9 & 2.8 \\
\hline $\begin{array}{l}\text { Years needed to } \\
\text { achieve WCEFA goal }\end{array}$ & 95 & 95 & 95 & 4.8 & 14.3 & 8.3 \\
\hline Year of achievement & 2093 & 2093 & 2093 & 2003 & 2012 & 2006 \\
\hline
\end{tabular}

Note: Interval between the two surveys is 5.5 years 